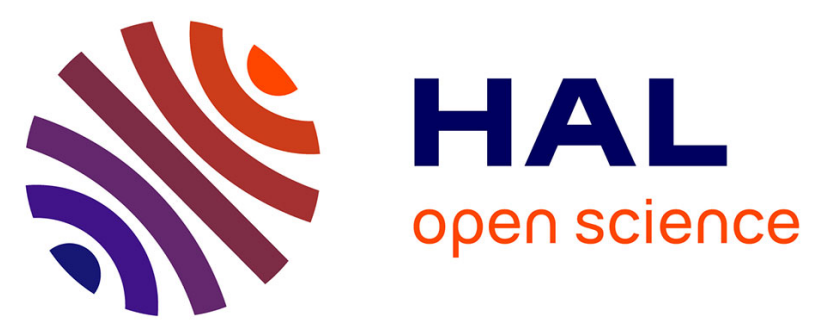

\title{
Radical-assisted polymerisation in interstellar ice analogues: formyl radical and polyoxymethylene
}

T. Butscher, Fabrice Duvernay, G. Danger, R Torro, G Lucas, Y Carissan, D. Hagebaum-Reignier, T Chiavassa

\section{- To cite this version:}

T. Butscher, Fabrice Duvernay, G. Danger, R Torro, G Lucas, et al.. Radical-assisted polymerisation in interstellar ice analogues: formyl radical and polyoxymethylene. Monthly Notices of the Royal Astronomical Society: Letters, 2019, 486 (2), pp.1953-1963. 10.1093/mnras/stz879 . hal-02151784

\section{HAL Id: hal-02151784 \\ https://hal-amu.archives-ouvertes.fr/hal-02151784}

Submitted on 10 Jun 2019

HAL is a multi-disciplinary open access archive for the deposit and dissemination of scientific research documents, whether they are published or not. The documents may come from teaching and research institutions in France or abroad, or from public or private research centers.
L'archive ouverte pluridisciplinaire HAL, est destinée au dépôt et à la diffusion de documents scientifiques de niveau recherche, publiés ou non, émanant des établissements d'enseignement et de recherche français ou étrangers, des laboratoires publics ou privés. 


\title{
Radical-assisted polymerisation in interstellar ice analogues : formyl radical and polyoxymethylene
}

\author{
T. Butscher, ${ }^{1}$ F. Duvernay, ${ }^{1 \star}$ G. Danger, ${ }^{1}$ R. Torro, ${ }^{2}$ G. Lucas, ${ }^{2}$ Y. Carissan, ${ }^{2}$ \\ D. Hagebaum-Reignier, ${ }^{2}$ and T. Chiavassa ${ }^{1}$ \\ ${ }^{1}$ Aix Marseille Univ, CNRS, PIIM, Marseille, France \\ ${ }^{2}$ Aix Marseille Univ, CNRS, Centrale Marseille, ISM2, Marseille, France
}

Accepted XXX. Received YYY; in original form ZZZ

\begin{abstract}
We present new laboratory experiments on the low-temperature formation of COMs such as polyoxymethylene (POM), glycolaldehyde (GA), ethylene glycol (EG) and possibly glyceraldehyde (GCA) and glycerol (GCO) through radical-induced reactivity from VUV photolysis of formaldehyde in Ar and Xe matrices. The radical reactivity and the endogenous formation of COMs were monitored in-situ via infrared spectroscopy in the solid state and post photolysis with temperature programmed desorption (TPD) using a quadripole mass spectrometer. Based on experimental finding and quantum calculations, we elaborate a formation pathway for formaldehyde polymerisation induced by radicals $\left({ }^{\circ} \mathrm{HCO}\right.$ and $\left.{ }^{\circ} \mathrm{CH}_{2} \mathrm{OH}\right)$ that support the POM formation in cometary environments. In addition, fragmentation patterns obtained from the sublimation of short chain-length POM are consistent with data collected by the Ptolemy instrument on-board the Rosetta mission and strengthen the POM identification made by this instrument.
\end{abstract}

Key words: Astrochemistry - Molecular processes-Comets:general- Methods: laboratory: molecular

\section{INTRODUCTION}

About 180 organic molecules were observed in the interstellar medium. They are generally simple molecules but almost 50 of them have 6 or more atoms and are called Complex Organic Molecules, hereafter COMs (Woods et al. 2013). Despite the large molecular diversity and complexity observed in space in most cases we are unaware of their formation mechanism. However, it is generally accepted that COMs form on the surfaces of icy dust grains. This idea is supported by laboratory results and astrochemical simulations, indicating that surface and bulk reactions induced by atom addition/abstraction, cosmic rays, VUV-photons, and by thermal processing are efficient processing for COMs formation in space.

In cold and dark environments (molecular clouds or dense cores), non-energetic processing mainly consists of atomic and hydrogenation reactions. One of the most well known reaction is the CO hydrogenation (Watanabe et al. 2003, 2004; Fuchs et al. 2009; Minissale et al. 2016):

$$
\mathrm{CO} \stackrel{H}{\rightarrow} \cdot \mathrm{HCO} \stackrel{H}{\rightarrow} \mathrm{H}_{2} \mathrm{CO} \stackrel{H}{\rightarrow} \cdot \mathrm{CH}_{2} \mathrm{OH} \stackrel{H}{\rightarrow} \mathrm{CH}_{3} \mathrm{OH}
$$

Along $\mathrm{H}$-atom addition reactions on $\mathrm{CO}$, two important radicals are formed ${ }^{\circ} \mathrm{HCO}$ and ${ }^{\circ} \mathrm{CH}_{2} \mathrm{OH}$. It has been recently proven that direct recombination ${ }^{\circ} \mathrm{HCO}$ and ${ }^{\circ} \mathrm{CH}_{2} \mathrm{OH}$ free radicals form glycolalde-

^ E-mail:fabrice.duvernay@univ-amu.fr hdye (GA, $\mathrm{HOCH}_{2} \mathrm{CHO}$ ), ethylene glycol (EG, $\mathrm{HOCH}_{2} \mathrm{CH}_{2} \mathrm{OH}$ ) (Butscher et al. 2015; Fedoseev et al. 2015; Chuang et al. 2015, 2017; Fedoseev et al. 2017). However, Butscher et al. (2017) recently showed that ${ }^{\circ} \mathrm{HCO}$ in astrophysical conditions is not able to dimerise into glyoxal (CHOCHO) but instead forms $\mathrm{CO}$ and $\mathrm{H}_{2} \mathrm{CO}$ :

$$
\begin{aligned}
{ }^{\circ} \mathrm{CH}_{2} \mathrm{OH}+{ }^{\cdot} \mathrm{HCO} & \rightarrow \mathrm{HOCH}_{2} \mathrm{CHO} \\
{ }^{\circ} \mathrm{CH}_{2} \mathrm{OH}+{ }^{\circ} \mathrm{CH}_{2} \mathrm{OH} & \rightarrow \mathrm{HOCH}_{2} \mathrm{CH}_{2} \mathrm{OH} \\
\cdot{ }^{\cdot} \mathrm{HCO}+{ }^{\cdot} \mathrm{HCO} & \rightarrow \mathrm{CO}+\mathrm{H}_{2} \mathrm{CO}
\end{aligned}
$$

Similar mechanisms based non-energetic processing and radical recombination in interstellar ice analogues can also result in the formation of biologically relevant molecules such as glyceraldehyde (GCA, $\left.\mathrm{HOCH}_{2}(\mathrm{OH}) \mathrm{CHO}\right)$ and glycerol (GCO, $\mathrm{HOCH}_{2} \mathrm{CH}(\mathrm{OH}) \mathrm{CH}_{2} \mathrm{OH}$ ) (Fedoseev et al. 2017). In this reaction scheme, carbon backbone increase is realized through recombination of CO-bearing radicals such as ${ }^{\circ} \mathrm{HCO}$ and ${ }^{\circ} \mathrm{CH}_{2} \mathrm{OH}$ on $\mathrm{HOCH}_{2} \mathrm{CHOH}$ intermediate radical formed from $\mathrm{H}$-atom addition/abstraction on GA and EG:

$$
\begin{gathered}
\mathrm{HOCH}_{2} \mathrm{CHO} \stackrel{+\mathrm{H}}{\longrightarrow} \mathrm{HOCH}_{2}{ }^{\circ} \mathrm{CHOH} \stackrel{{ }^{\circ} \mathrm{HCO}}{\longrightarrow} \mathrm{HOCH}_{2} \mathrm{CH}(\mathrm{OH}) \mathrm{CHO} \\
\mathrm{HOCH}_{2} \mathrm{CH}_{2} \mathrm{OH} \stackrel{-\mathrm{H}}{\longrightarrow} \mathrm{HOCH}_{2}{ }^{\circ} \mathrm{CHOH} \stackrel{\mathrm{CH}_{2} \mathrm{OH}}{\longrightarrow} \mathrm{HOCH}_{2} \mathrm{CH}(\mathrm{OH}) \mathrm{CH}_{2} \mathrm{OH}
\end{gathered}
$$

Energetic processing (photons, electrons, X-rays) that are prominent during later stages of the star and planet formation process can also trigger reactive intermediates and radicals formation. It has been extensively shown that laboratory experiments on $\mathrm{CH}_{3} \mathrm{OH}$-rich ice analogues exposed to such energetic processing 
can efficiently produce a large diversity of COMs including amino acids and sugars. (Caro et al. 2002; Öberg et al. 2009; Abou Mrad et al. 2014, 2016; Kaiser et al. 2015; Henderson \& Gudipati 2015; Chuang et al. 2017).

COMs are also detected in comets that harbor the most pristine material in our solar system that may have preserved their interstellar heritage (Goesmann et al. 2015; Wright et al. 2015; Biver et al. 2014; Crovisier et al. 2004; Huebner 1987) as recently revealed by the Rosetta mission. Twenty five minutes after lander Philae's initial comet touchdown onto comet 67P/Churyumov-Gerasimenko, COSAC instruments performed analyses that displayed 16 organic compounds -including CHO-bearing molecules such as glycolaldehyde (GA) and ethylene glycol (EG)- while Ptolemy instrument detected regular mass distributions suggesting the presence of a radiation-induced POM-like polymer (Wright et al. 2015). This backs up analysis made with the PICCA instruments on comet Halley during the Giotto mission where a similar regular pattern of peaks has been observed, which was also tentatively assigned at that time to POM-like structures (Huebner 1987). Even if the POM detection by both Rosetta and Giotto missions is controversial (Mitchell et al. 1989; Altwegg et al. 2017), the presence of POM in comets (Schutte et al. 1993) cannot be excluded. First, it is so far the best candidate to explain the distributed source of $\mathrm{CO}$ and formaldehyde observed in coma (Cottin \& Fray 2008; Fray et al. 2006). It is also supported by laboratory experiments. POM and POM-like polymers can be easily formed from the heating of interstellar/cometary ice analogs containing $\mathrm{H}_{2} \mathrm{CO}, \mathrm{H}_{2} \mathrm{O}$, and a nucleophile $\left(\mathrm{NH}_{3}, \mathrm{CN}^{-}\right)$(Schutte et al. 1993; Danger et al. 2014; Noble et al. 2012; Vinogradoff et al. 2011; Duvernay et al. 2014) or from UV irradiation of interstellar/cometary ice analogues containing formaldehyde (Butscher et al. 2016).

Thus, by exposing energetic and non-energetic processing on ice analogues, COMs formation is indeed observed but almost no reaction intermediates are identified this way (Schutte et al. 1993; Butscher et al. 2016; Bennett \& Kaiser 2007). To solve this problem, we resort to the cryogenic matrix technique. Already used before for the characterisation of radicals of astrophysical interest (Milligan \& Jacox 1969; Hiraoka et al. 1995; Pirim \& Krim 2011; Lee et al. 2015), it consists in trapping the starting material in a rare gas matrix and submitting it to energetic processes. This way, all species are isolated from one another in a cold environment. This technique has two advantages. First, the way the molecules are isolated prevents them from rotating freely so that most of rotational contributions are removed and no intermolecular interactions are possible if molecules are present in monomeric form in their cage. The resulting spectrum becomes close to that of gas phase without rotational structure. Also, since trapped molecules are alone in their cage, reactive species are not able to find a partner to react with, so when radical species are produced, their lifetime and stability in the rare gas matrix are greatly increased, making their characterisation easier with infrared spectroscopy. Then, by quickly removing the rare gas cages, radicals and reactive species are free to react and recombine (Butscher et al. 2015, 2017).

The objective of the present work is to go further in the understanding of the reactivity of small organic radicals. Using cryogenic matrix technique, we specifically study the formaldehyde polymerisation initiated by radicals that might explain some observations made on comet 67P/Churyumov-Gerasimenko by the Ptolemy instrument on-aboard Rosetta's lander Philae (Wright et al. 2015) or on Halley comet by the Giotto mission. The experimental setup is described in section 2 and the results of each step of our experiments as well as theoretical calculations are detailed in section 3. Discus- sion includes a confrontation with astrophysical observations and implications.

\section{EXPERIMENTAL AND COMPUTATIONAL METHODS}

\subsection{Experimental details}

Argon an Xenon (99.999 \% of purity) used as matrix rare gas ( $\mathrm{Rg}$ ) were purchased from Air Liquide. Formaldehyde was purchased as a polymer from Sigma Aldrich (99.95\% of purity) and was heated to about $90^{\circ} \mathrm{C}$ to produce the gas-phase monomer. For references, glycolaldehyde was purchased as a dimer from Sigma Aldrich ( $99.95 \%$ of purity) and heated under vacuum to about $80^{\circ} \mathrm{C}$ to produce gas-phase monomer. Ethylene glycol was purchased from Sigma Aldrich. The experimental AHIIA system has already been described precisely in a previous article (Butscher et al. 2015).

All experiments described are performed in a high vacuum chamber with a background pressure of $10^{-8}$ mbar at $295 \mathrm{~K}$ and $10^{-9} \mathrm{mbar}$ at $13 \mathrm{~K}$. The temperature is controlled using a model 21 CTI cold head, a resistive heater and a Lakeshore 331 temperature controller. Products were mixed in $2 / 1000$ ratio of $\mathrm{H}_{2} \mathrm{CO} / \mathrm{Rg}$ in a Pyrex vacuum line using standard manometric techniques. Gaseous mixtures were deposited at a rate of $510^{-2} \mathrm{mbar} \mathrm{s}^{-1}$ on a goldplated surface kept at $30 \mathrm{~K}$ for xenon experiments and $13 \mathrm{~K}$ for argon experiments. Glycolaldehyde and ethylene glycol solid films can be obtained by directly dosing them onto the sample holder in order to get spectroscopic references. POM used for spectroscopic reference is produced directly onto sample holder by a thermallyinduced formaldehyde polymerisation catalysed by ammonia (Duvernay et al. 2014; Schutte et al. 1993).

Radicals are produced from the VUV photolysis of formaldehyde $\mathrm{H}_{2} \mathrm{CO}$ in a rare gas matrix. The VUV photons are generated from a microwave induced low pressure $\mathrm{H}_{2}$ plasma using a microwave magnetic applicator (Boreal Plasma) fed by a microwave generator (Opthos instruments). In a such low pressure $\mathrm{H}_{2}$ plasma (20 $10^{-3}$ mbar), the VUV emission is dominated by Lyman alpha photons at $121.6 \mathrm{~nm}$ but molecular $\mathrm{H}_{2}$ emission at $160 \mathrm{~nm}$ cannot be excluded. The VUV flux is transmitted from the plasma chamber to the vacuum chamber through an $\mathrm{MgF}_{2}$ window. The photon flux has been measured using the $\mathrm{O}_{2} \rightarrow \mathrm{O}_{3}$ actinometry method (Cottin et al. 2003) to c.a. $2.510^{13}$ photons $\mathrm{cm}^{-2} \mathrm{~s}^{-1}$, which is $10^{10}$ times larger than the UV secondary flux in dense molecular clouds.

The sample are monitored using a Bruker Tensor 27 FTIR spectrometer with MCT detector between 4000 and $600 \mathrm{~cm}^{-1}$ in reflection mode (reflection angle $<5^{\circ}$ ) which can be considered as double transmission technique since the infrared beam angle of incidence is closed to the normal. Each spectrum was averaged over 20 scans with a $0.5 \mathrm{~cm}^{-1}$ resolution, except for the background averaged over one hundred scans with the same resolution. The quantification of products observed in the solid film after rare gas desorption is based on infrared analysis. The column density $\mathcal{N}$ (molecule $\mathrm{cm}^{-2}$ ) can be determined by integrating either the absorbance $\mathrm{A}(v)$ or the optical depth $\tau(v)$, according to the equations: $\mathcal{N}=\frac{\int \tau(v)}{2 \cos (5) \mathcal{F}}=\frac{\ln (10) \int A(v)}{2 \cos (5) \mathcal{F}}$, where $\mathcal{F}$ is the band strength (cm molecule ${ }^{-1}$ ) and $\ln (10)$ is needed to convert the integrated absorbance to optical depth. The column density of GA is obtained from the IR band at $1746 \mathrm{~cm}^{-1}\left(\mathcal{F}=2.6 \times 10^{-17} \mathrm{~cm}\right.$ molecule $\left.{ }^{-1}\right)$, the amount of EG is obtained from the IR band at 1089 $\mathrm{cm}^{-1}$ with a strength $\mathcal{F}=3.9 \times 10^{-18} \mathrm{~cm}$ molecule ${ }^{-1}$ (Hudson et al. 2005), and the amount of POM is obtained from the IR band at 902 
$\mathrm{cm}^{-1}$ with a strength $\mathcal{F}=5 \times 10^{-19} \mathrm{~cm}$ molecule ${ }^{-1}$ (Schutte et al. 1993). It has to be noted that the values of the band strengths depend on the nature, composition, and temperature of the ice in which they are found, and this dependence is a major source of uncertainties when evaluating the column densities of frozen molecules.

All the experiments described below were done in three steps : (i) Radical formation from VUV photolysis of radical precursor formaldehyde; (ii) Rare gas matrices annealing; (iii) Rare gas desorption at $35 \mathrm{~K}$ for argon and $85 \mathrm{~K}$ for xenon. After rare gas desorption, a ramp of $4 \mathrm{~K} \mathrm{~min}^{-1}$ is applied while the ion current is recorded from RGA quadrupole mass spectrometer (MKS Microvision-IP plus) to obtain a full temperature programmed desorption (TPD) profile, relative to various products. The ionisation source was a $70 \mathrm{eV}$ impact electronic source and the mass spectra were recorded between 1 and 100 amu in a full scan.

\subsection{Computational details}

Density Functional Theory (DFT) and coupled-cluster calculations were performed using the Turbomole V7.2 package. The structures of the reactants, transition states and products were fully optimised using the Becke's three-parameter hybrid functional (B3LYP) (Becke 1993) in an unrestricted formalism, along with the dev2-TZVP basis set (Weigend \& Ahlrichs 2005). These structures were caracterised by vibrational harmonic frequencies and zero-point energies (ZPE) calculated at the same level of theory using the aoforce module (Deglmann et al. 2004).

For all stationary points, single-point calculations were carried out at the explicitly correlated Unrestricted Coupled Cluster Single and Double with inclusion of a perturbative estimation for triple excitations (UCCSD(T)-F12) (Tew \& Klopper 2010) level along with the cc-pVTZ basis set (Dunning 1989). Explicitly correlated (F12) methods allow rapid orbital convergence and can lead to near basis set limit accuracy using small basis sets, with a small extra computational cost compared to conventional methods (Hättig et al. 2012). They are very useful for benchmarking, especially in the field of thermochemistry, and have proven to be highly accurate for astrochemically relevant systems (Stein et al. 2015).

\section{RESULTS AND DISCUSSION}

\subsection{Experimental results}

\subsubsection{Formaldehyde photolysis at $\lambda>120 \mathrm{~nm}$ : radicals formation in argon and xenon matrices}

A gaseous mixture of formaldehyde and argon in a 2/1000 ratio is deposited on a cold surface ( $13 \mathrm{~K}$ in our case) at low pressure $\left(10^{-8}\right.$ mbar) with a controlled flow rate. In Ar matrix, the main bands of $\mathrm{H}_{2} \mathrm{CO}$ are observed at 2864, 2798, 1742 and $1499 \mathrm{~cm}^{-1}$ (negative bands in Fig. 1, Table 1). These absorptions correspond to asymmetric and symmetric $\mathrm{CH}$ stretching mode, $\mathrm{C}=\mathrm{O}$ stretching mode and $\mathrm{CH}$ bending mode respectively and are down-shifted with ${ }^{12} \mathrm{C}$ to ${ }^{13} \mathrm{C}$ isotopic change (Milligan \& Jacox 1969). The corresponding values in Xe matrix are listed in Table 1. We assume that formaldehyde is trapped as monomer inside the matrix since the infrared signatures of formaldehyde dimer are not detected after the deposition (Nelander 1980). In this work, we tried to figure out the reactivity of formyl radical ${ }^{*} \mathrm{HCO}$ when the main reactivity partner is formaldehyde $\mathrm{H}_{2} \mathrm{CO}$. To make it possible, we performed an VUV irradiation $(\lambda>120 \mathrm{~nm})$ at low fluence $\left(2.710^{18}\right.$ photons $\mathrm{cm}^{-2}$ corresponding to $30 \mathrm{~min}$ of irradiation) of $\mathrm{H}_{2} \mathrm{CO}$ trapped in
Table 1. Infrared absorption bands and assignments of $\mathrm{H}_{2} \mathrm{CO}$ in $\mathrm{Ar}$ and $\mathrm{Xe}$ matrices at $13 \mathrm{~K}$.

\begin{tabular}{|c|c|c|c|c|}
\hline \multicolumn{4}{|c|}{ Wavenumbers $\left(\mathrm{cm}^{-1}\right)$} & \multirow[b]{3}{*}{ Assignments } \\
\hline \multicolumn{2}{|c|}{$\mathrm{Ar}$} & \multicolumn{2}{|c|}{$\mathrm{Xe}$} & \\
\hline${ }^{12} \mathrm{C}$ & ${ }^{13} \mathrm{C}$ & ${ }^{12} \mathrm{C}$ & ${ }^{13} \mathrm{C}$ & \\
\hline 3464 & 3389 & 3449 & 3375 & $2 v(\mathrm{CO})$ \\
\hline 2997 & 2954 & 2980 & 2944 & $2 \delta(\mathrm{CH})$ \\
\hline 2864 & 2846 & 2837 & 2822 & $v(\mathrm{CH})-\mathrm{a}$ \\
\hline 2798 & 2793 & 2771 & 2767 & $v(\mathrm{CH})-\mathrm{s}$ \\
\hline 2719 & 2708 & 2701 & 2691 & \\
\hline 1742 & 1704 & 1735 & 1697 & $v(\mathrm{CO})$ \\
\hline 1499 & 1499 & 1491 & 1491 & $\delta(\mathrm{CH})$ \\
\hline 1245 & 1235 & 1238 & 1232 & $\rho(\mathrm{CH})$ \\
\hline 1168 & 1156 & 1163 & 1151 & $\omega(\mathrm{CH})$ \\
\hline
\end{tabular}

$v$ : stretching; $\delta$ : bending; $\rho$ : rocking; $\omega$ : wagging.

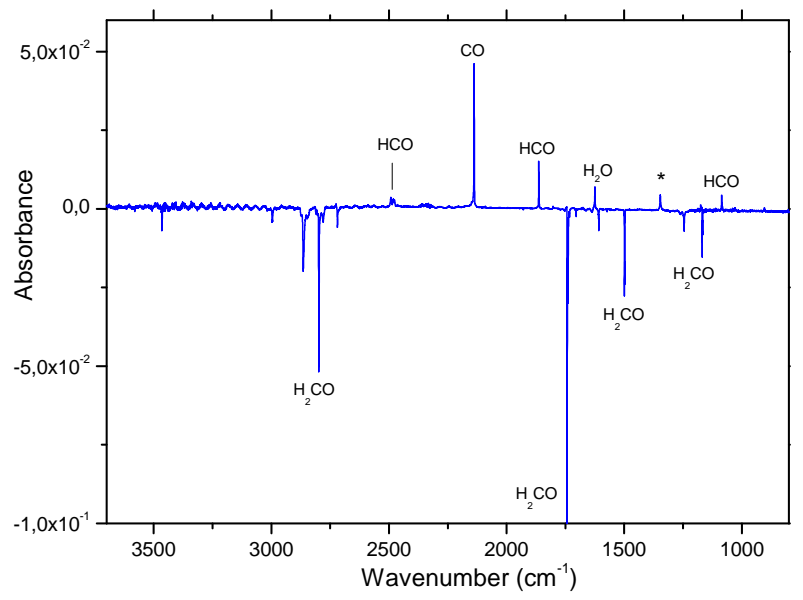

Figure 1. Difference infrared spectrum after VUV photolysis ( $30 \mathrm{~min}, \lambda>120$ $\mathrm{nm}$ ) at $12 \mathrm{~K}$ in $\mathrm{Ar}$ matrix. Negative bands stand for $\mathrm{H}_{2} \mathrm{CO}$, while positive bands stand for photo-products. Bands labeled with stars refer to unknown species.

rare gas matrices. This way, only $7 \%$ of formaldehyde is consumed and photo-products are then produced.

Figure 1 displays the difference spectrum showing the effects of VUV irradiation in Ar matrix. The negative bands in Fig. 1 are due to the consumed formaldehyde and the positive bands to the newly formed products. Table 2 displays IR assignments of products observed after ${ }^{12} \mathrm{C}$ and ${ }^{13} \mathrm{C}$ formaldehyde photolysis in both $\mathrm{Ar}$ and Xe matrices. $\mathrm{HCO}$ radical is clearly identified in ${ }^{12} \mathrm{C}$ experiments by the bands in Ar matrix at $2482 \mathrm{~cm}^{-1}, 1863 \mathrm{~cm}^{-1}$ and $1085 \mathrm{~cm}^{-1}$, corresponding to its $\mathrm{CH}$ stretching, $\mathrm{C}=\mathrm{O}$ stretching and $\mathrm{CHO}$ bending vibrational modes respectively (Milligan \& Jacox 1969) (Table 2, Fig. 1). The corresponding value in Xe matrix and for ${ }^{13} \mathrm{C}$ experiments are listed in Table 2. $\mathrm{CO}$ and $\mathrm{CO}_{2}$ are also visible and characterised by their bands in Ar matrix at $2138 \mathrm{~cm}^{-1}$ and $2345 \mathrm{~cm}^{-1}$ respectively, corresponding to the $\mathrm{CO}$ stretching mode (Abe et al. 1999; Schriver et al. 2000). Finally, a band at 
Table 2. Infrared absorption bands and assignments of produced species after ${ }^{12} \mathrm{C}$ and ${ }^{13} \mathrm{C}$ formaldehyde photolysis $(\lambda>120 \mathrm{~nm}, 30 \mathrm{~min})$ at $12 \mathrm{~K}$ in Ar and Xe matrices.

\begin{tabular}{|c|c|c|c|c|c|}
\hline \multicolumn{4}{|c|}{ Wavenumbers $\left(\mathrm{cm}^{-1}\right)$} & \multirow[b]{3}{*}{ Modes } & \multirow[b]{3}{*}{ Species } \\
\hline \multicolumn{2}{|c|}{ Ar } & \multicolumn{2}{|c|}{$\mathrm{Xe}$} & & \\
\hline${ }^{12} \mathrm{C}$ & ${ }^{13} \mathrm{C}$ & ${ }^{12} \mathrm{C}$ & ${ }^{13} \mathrm{C}$ & & \\
\hline 2482 & 2476 & 2442 & 2436 & $v(\mathrm{CH})$ & ${ }^{\circ} \mathrm{HCO}$ \\
\hline 2345 & 2279 & 2334 & 2269 & $v(\mathrm{CO})$ & $\mathrm{CO}_{2}$ \\
\hline 2138 & 2091 & 2133 & 2086 & $v(\mathrm{CO})$ & $\mathrm{CO}$ \\
\hline 1863 & 1823 & 1857 & 1817 & $v(\mathrm{CO})$ & ${ }^{\circ} \mathrm{HCO}$ \\
\hline 1624 & 1624 & & & $\delta(\mathrm{OH})$ & $\mathrm{H}_{2} \mathrm{O}$ \\
\hline 1346 & 1346 & & & $?$ & $?$ \\
\hline \multirow[t]{2}{*}{1085} & 1078 & 1082 & 1076 & $\delta(\mathrm{CHO})$ & ${ }^{\circ} \mathrm{HCO}$ \\
\hline & & 953 & 953 & $v(\mathrm{XeH})$ as & $\mathrm{Xe}_{2} \mathrm{H}^{+}$ \\
\hline \multirow[t]{3}{*}{903} & 903 & & & $v(\mathrm{ArH})$ as & $\mathrm{Ar}_{2} \mathrm{H}^{+}$ \\
\hline & & 843 & 843 & $v(\mathrm{XeH})$ as & $\mathrm{Xe}_{2} \mathrm{H}^{+}$ \\
\hline & & 731 & 731 & $v(\mathrm{XeH})$ as & $\mathrm{Xe}_{2} \mathrm{H}^{+}$ \\
\hline
\end{tabular}

$\nu$ : stretching; $\delta$ : bending; $\rho$ : rocking; $\omega$ : wagging; $\tau$ : twisting.

$903 \mathrm{~cm}^{-1}$ is detected after photolysis in Ar matrix. Its intensity increases with the irradiation duration, proving that it is a product from VUV photolysis. According to Kunttu et al. (1992), this band can be assigned to $\mathrm{Ar}_{2} \mathrm{H}^{+}$since small hydrides are known to form ionic complexes in rare gas matrices (Pettersson et al. 2000). When photolysis is performed in Xe matrix three bands are observed at 952, 842, and $730 \mathrm{~cm}^{-1}$ assigned to $\mathrm{Xe}_{2} \mathrm{H}^{+}$(Pettersson et al. 2000). Thus, the main radical species formed in both Ar and Xe matrices at low fluence in a $\mathrm{H}_{2} \mathrm{CO}$-dominated environment is the formyl radical ('HCO).

\subsubsection{Matrix annealing : in situ hydrogenation reactions}

The second step of our experiment is an annealing step, in which we heat at $30 \mathrm{~K}$ ( $50 \mathrm{~K}$ in Xe matrix) during $10 \mathrm{~min}$ without desorbing the matrix and then cool down the system back to $13 \mathrm{~K}$. This way, all H-atoms - formed during the formaldehyde photolysis - will diffuse through the matrix and will react whenever a partner is met. New species coming from hydrogenation reactions within the rare gas matrices are then detected on the infrared spectrum. This technique has been already successfully used in our previous work to form the hydroxymethyl radical ${ }^{\circ} \mathrm{CH}_{2} \mathrm{OH}$ from in situ hydrogenation reactions of formaldehyde (Butscher et al. 2015, 2016). During the annealing small molecules or small radicals may also be able to exit from their matrix cage but because of the high dilution used in our experiments they will enter in a matrix cage that is most likely empty. In these particular conditions radical-radical recombination are unlikely and only products coming from reaction with $\mathrm{H}$-atoms, the most diffusive species, are expected.

Annealing the irradiated sample results in noticeable changes in the difference IR spectrum (Fig. 2). The study is focused on the $1400-1000 \mathrm{~cm}^{-1}$ zone of the difference spectrum, known as the fingerprint zone, to make the assignment easier. New products formed from in situ hydrogenation reactions are shown as positive bands

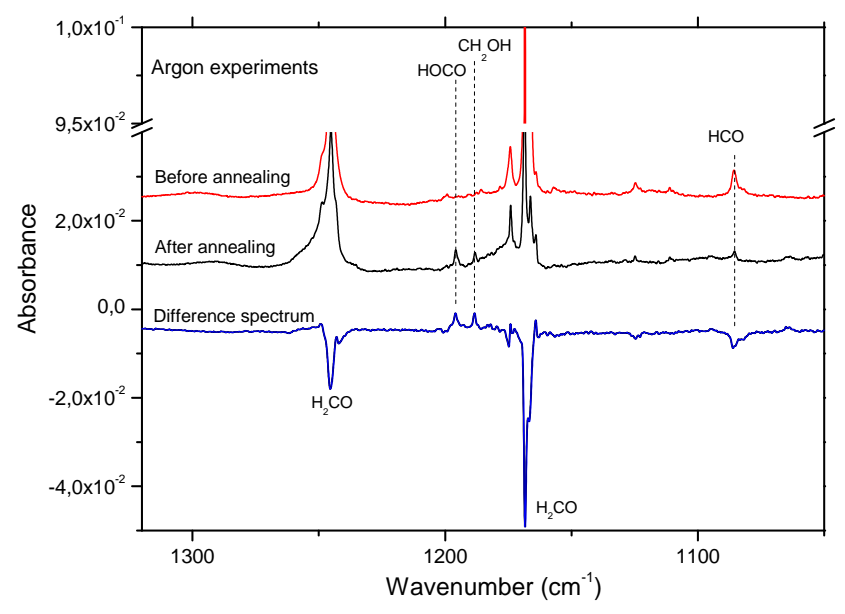

Figure 2. Infrared difference spectrum showing the effect of annealing at $30 \mathrm{~K}$ after the VUV photolysis $(\lambda>120 \mathrm{~nm}, 30 \mathrm{~min})$ of formaldehyde in Ar matrix. Positive bands relates to formed species and negatives bands to consumed species

on the difference spectrum in Figure 2, whereas negative bands relate to consumed species. Infrared frequencies and assignments of present species after annealing step are listed on Table 3 along with their evolutions during the annealing. This annealing step makes the $\mathrm{Ar}_{2} \mathrm{H}^{+}$band at $903 \mathrm{~cm}^{-1}$ disappears (the same is true with $\mathrm{Xe}_{2} \mathrm{H}^{+}$in Xe matrix experiments), proving that all $\mathrm{H}$-atoms reacted (Butscher et al. 2015; Pettersson et al. 2000). Due to the low fluence used in our experiments, only a low amount of free $\mathrm{H}$-atoms were produced. However, $\mathrm{CO}$ is still partially consumed to form ${ }^{\circ} \mathrm{HCO}$ by hydrogenation reactions since $\mathrm{CO}$ band at $2138 \mathrm{~cm}^{-1}$ decreases during the annealing (Table 3 ). This radical will also be partially hydrogenated to form formaldehyde $\mathrm{H}_{2} \mathrm{CO}$. However, as seen in Fig. 2, the ${ }^{\circ} \mathrm{HCO}$ radical is still present after the annealing in the matrix.

A new radical species appears by the hydrogenation of formaldehyde $\mathrm{H}_{2} \mathrm{CO}$. Hydroxymethyl radical ${ }^{\circ} \mathrm{CH}_{2} \mathrm{OH}$ is detected in Ar matrix from its bands at 1358,1183 , and $1048 \mathrm{~cm}^{-1}$ corresponding to its $\mathrm{HOC}$ bending mode, $\mathrm{CH}$ bending mode, and $\mathrm{HCOH}$ bending mode respectively. These assignments are in good agreement with previous works and are confirmed in ${ }^{13} \mathrm{C}$ and xenon experiments (Butscher et al. 2015; Jacox \& Milligan 1973) (Table. 3. A band at $1188 \mathrm{~cm}^{-1}$ is also detected. It is assigned to the $\mathrm{CH}$ bending mode of ${ }^{\circ} \mathrm{CH}_{2} \mathrm{OH}: \mathrm{CO}$ molecular complex (Butscher et al. 2015). As only a few free $\mathrm{H}$-atoms were formed, only a small amount of ${ }^{\circ} \mathrm{CH}_{2} \mathrm{OH}$ is produced whereas methanol $\mathrm{CH}_{3} \mathrm{OH}$-the fully saturated molecule in the $\mathrm{CO}$ hydrogenation chain- is not detected. Another radical is also detected ${ }^{\circ} \mathrm{HOCO}$ from its bands located at $1843 \mathrm{~cm}^{-1}$ in Ar matrix(Jacox 1988; Ryazantsev \& Feldman 2014). A small band at $1195 \mathrm{~cm}^{-1}$ (Fig. 2) is tentatively assigned to the HOC bending mode of "HOCO:CO molecular complex (Jacox 1988; Ryazantsev \& Feldman 2014). At this stage, the present molecules are $\mathrm{H}_{2} \mathrm{CO},{ }^{\circ} \mathrm{HCO}, \mathrm{CO}, \mathrm{CO}_{2},{ }^{\circ} \mathrm{CH}_{2} \mathrm{OH}$, and ${ }^{\bullet} \mathrm{HOCO}$.

\subsubsection{Radical induced polymerisation : reactivity with an unsaturated molecule}

The last step of our experiments is the rare gas desorption. The rare gas matrices are quickly heated at $35 \mathrm{~K}$ for $\mathrm{Ar}$ and $85 \mathrm{~K}$ for Xe, making the matrix cages disappear forming an amorphous solid film 
Table 3. Infrared absorption bands and assignments of present species after annealing step (heating to $30 \mathrm{~K}$ in Ar matrix and $55 \mathrm{~K}$ in Xe matrix and cooling down back to $12 \mathrm{~K}$ ).

\begin{tabular}{|c|c|c|c|c|c|c|}
\hline \multicolumn{5}{|c|}{ Wavenumbers $\left(\mathrm{cm}^{-1}\right)$} & \multirow[b]{3}{*}{ Species } & \multirow[b]{3}{*}{$\begin{array}{c}\text { Bands } \\
\text { evolution* }\end{array}$} \\
\hline \multicolumn{2}{|c|}{$\mathrm{Ar}$} & \multicolumn{2}{|c|}{$\mathrm{Xe}$} & \multirow[b]{2}{*}{ Modes } & & \\
\hline${ }^{12} \mathrm{C}$ & ${ }^{13} \mathrm{C}$ & ${ }^{12} \mathrm{C}$ & ${ }^{13} \mathrm{C}$ & & & \\
\hline 2482 & 2476 & 2442 & 2431 & $v(\mathrm{CH})$ & ${ }^{\circ} \mathrm{HCO}$ & $y$ \\
\hline 2345 & 2279 & 2334 & 2269 & $v(\mathrm{CO})$ & $\mathrm{CO}_{2}$ & $\pi$ \\
\hline 2138 & 2091 & 2133 & 2086 & $v(\mathrm{CO})$ & $\mathrm{CO}$ & $y$ \\
\hline 1863 & 1823 & 1857 & 1817 & $v(\mathrm{CO})$ & ${ }^{\circ} \mathrm{HCO}$ & $y$ \\
\hline 1843 & - & - & - & $v(\mathrm{CO})$ & HOCO & 入 \\
\hline 1358 & 1355 & 1355 & 1350 & $\delta(\mathrm{HOC})$ & $\cdot \mathrm{CH}_{2} \mathrm{OH}$ & 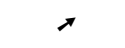 \\
\hline 1195 & - & - & - & $\delta(\mathrm{HOC})$ & HOCO:CO & 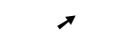 \\
\hline 1188 & - & - & - & $\delta(\mathrm{CH})$ & $\cdot{ }^{\circ} \mathrm{CH}_{2} \mathrm{OH}: \mathrm{CO}$ & 入 \\
\hline 1183 & 1176 & 1176 & 1162 & $\delta(\mathrm{CH})$ & $\cdot \mathrm{CH}_{2} \mathrm{OH}$ & $\pi$ \\
\hline 1085 & 1078 & 1082 & 1076 & $\delta(\mathrm{CHO})$ & ${ }^{\circ} \mathrm{HCO}$ & $y$ \\
\hline 1048 & - & 1044 & 1040 & $\delta(\mathrm{CHOH})$ & $\cdot \mathrm{CH}_{2} \mathrm{OH}$ & $\pi$ \\
\hline
\end{tabular}

$v$ : stretching; $\delta$ : bending. *: Infrared bands evolution during the annealing at $30 \mathrm{~K}$.

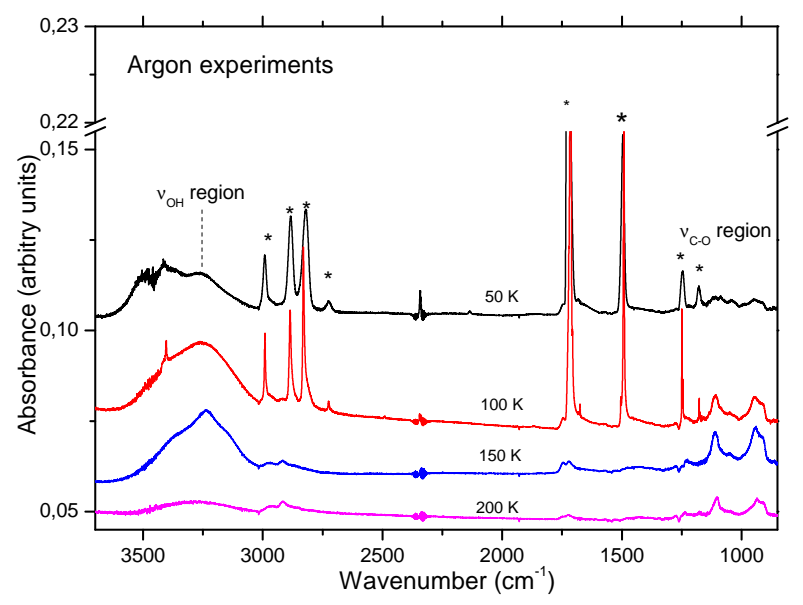

Figure 3. Infrared spectrum of the solid film obtained after argon desorption $(35 \mathrm{~K}$ ) from the sample recorded during the warming from 50 to $200 \mathrm{~K}$ (4 $\mathrm{K} \mathrm{min}^{-1}$ ). Bands labeled with stars are due to formaldehyde.

in which freed radicals will then react with other partners from rad$\mathrm{ical} /$ radical and radical/non-radical reactions, forming new species. Figure 3 (top spectrum) displays the solid film infrared spectrum recorded after Ar desorption at $50 \mathrm{~K}$. As expected, it is dominated by $\mathrm{H}_{2} \mathrm{CO}$ signatures but new infrared contributions are also visible at $3238 \mathrm{~cm}^{-1}$ in the $\mathrm{OH}$ stretching region and at 1116,941, and 905 $\mathrm{cm}^{-1}$ in the $\mathrm{C}-\mathrm{O}$ stretching region. (Fig. 3, top spectrum). The solid obtained after Ar desorption at $50 \mathrm{~K}$ is warmed at a rate of $4 \mathrm{~K}$ $\min ^{-1}$. The infrared spectra recorded at specific temperatures $(100$, 150 , and $200 \mathrm{~K}$ ) are displayed in Figure 3. Between 50 and $100 \mathrm{~K}$, the most striking differences are the increase of bands located at 1116,941 , and $905 \mathrm{~cm}^{-1}$ in the CO stretching region and the refinement of infrared absorption bands of formaldehyde mainly due to

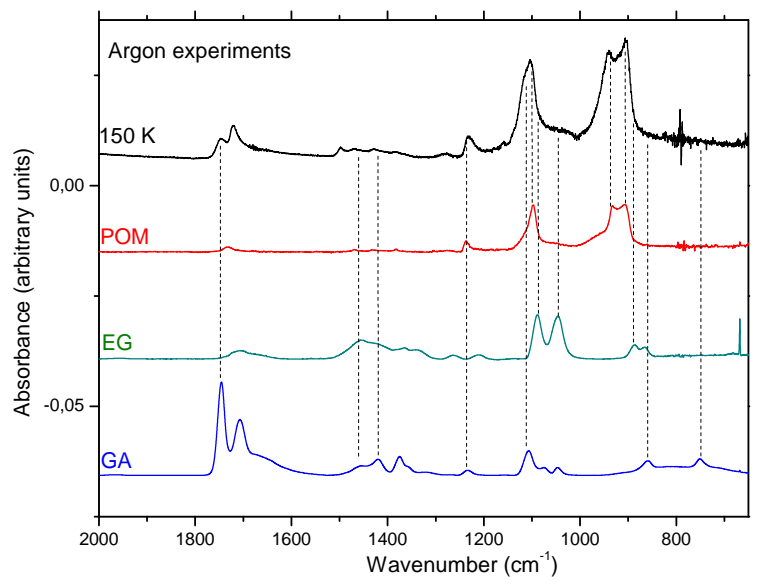

Figure 4. Infrared spectrum of the solid film recorded at $150 \mathrm{~K}$ after Ar desorption from the sample at $35 \mathrm{~K}$. It is compared to reference spectra of polyoxymethylene, ethylene glycol, and glycolaldehyde

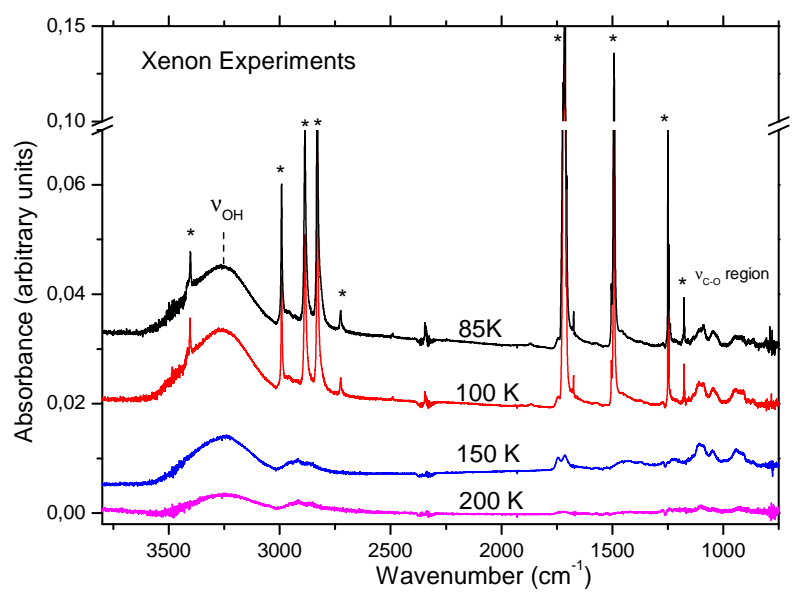

Figure 5. Infrared spectrum of the solid film obtained after xenon desorption $(85 \mathrm{~K})$ from the sample recorded during the warming from 85 to $200 \mathrm{~K}$ (4 $\mathrm{K} \mathrm{min}^{-1}$ ). Bands labeled with stars are due to formaldehyde.

crystallisation of the solid film. At $150 \mathrm{~K}$, the bands of formaldehyde are not present due to its desorption from the sample holder (Fig. 3). In order to determine the new-formed species, attributions are made on the $2000-700 \mathrm{~cm}^{-1}$ area that is a more characteristic region for identification. In this figure, the IR spectrum recorded at $150 \mathrm{~K}$ after formaldehyde desorption is compared with reference spectra of polyoxymethylene (POM), ethylene glycol (EG, $\mathrm{HOCH}_{2} \mathrm{CH}_{2} \mathrm{OH}$ ), and glycolaldehyde $\left(\mathrm{GA}, \mathrm{C}(\mathrm{O}) \mathrm{HCH}_{2} \mathrm{OH}\right)$ (Fig 4). As seen on Figure 4 (top spectrum), the bands at 1116,941 , and $905 \mathrm{~cm}^{-1}$ can easily be identified as $\mathrm{C}-\mathrm{O}$ stretching modes of formaldehyde polymer polyoxymethylene (POM) (Schutte et al. 1993; Duvernay et al. 2014). Apparently, the low amount of radicals ( ${ }^{\mathrm{HCO}},{ }^{\circ} \mathrm{CH}_{2} \mathrm{OH}$, etc) is sufficient to initiate chain-propagating $\mathrm{H}_{2} \mathrm{CO}$ polymerization reactions right after the rare gas sublimation but also during the warming. Finally the bands of POM start to decrease around $180 \mathrm{~K}$ and totally disappear after $250 \mathrm{~K}$ (Fig. 3). This is due to POM sublimation and thermal decomposition into formaldehyde (Duvernay et al. 2014).

Glycolaldehyde $\left(\mathrm{GA}, \mathrm{C}(\mathrm{O}) \mathrm{HCH}_{2} \mathrm{OH}\right)$ and ethylene glycol $\left(\mathrm{EG}, \mathrm{HOCH}_{2} \mathrm{CH}_{2} \mathrm{OH}\right)$ are also detected in this experiment. Im- 


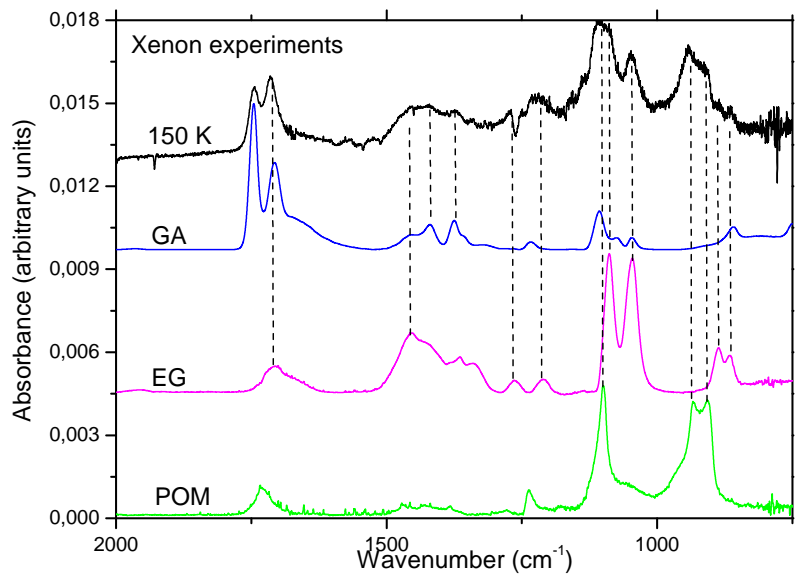

Figure 6. Infrared spectrum of the solid film recorded at $150 \mathrm{~K}$ after Xenon desorption from the sample at $85 \mathrm{~K}$. It is compared to reference spectra of polyoxymethylene, ethylene glycol, and glycolaldehyde. See experimental part for details.

Table 4. Infrared absorption bands and assignments of present species in the solid film at $50 \mathrm{~K}$.

\begin{tabular}{cccc}
\hline \hline \multicolumn{2}{c}{ Wavenumbers $\left(\mathrm{cm}^{-1}\right)$} & & \\
\cline { 1 - 2 }${ }^{12} \mathrm{C}$ & ${ }^{13} \mathrm{C}$ & Assignments & Molecules \\
\cline { 1 - 2 } 3238 & 3235 & $v(\mathrm{OH})$ & $\mathrm{EG}+\mathrm{GA}+\mathrm{POM}$ \\
2992 & 2958 & $2 \delta(\mathrm{CH})$ & $\mathrm{H}_{2} \mathrm{CO}$ \\
2863 & 2958 & $v(\mathrm{CH})$ & $\mathrm{H}_{2} \mathrm{CO}$ \\
2821 & 2816 & $v(\mathrm{CH})$ & $\mathrm{H}_{2} \mathrm{CO}$ \\
2343 & 2275 & $v(\mathrm{C}=\mathrm{O})$ & $\mathrm{CO}_{2}$ \\
2136 & 2090 & $v(\mathrm{CO})$ & $\mathrm{CO}$ \\
1746 & 1716 & $v(\mathrm{C}=\mathrm{O})$ & $\mathrm{GA}$ \\
1725 & 1690 & $v(\mathrm{C}=\mathrm{O})$ & $\mathrm{H}_{2} \mathrm{CO}$ \\
1699 & 1661 & $?$ & $\mathrm{GA}$ \\
1495 & 1495 & $\delta(\mathrm{CH})$ & $\mathrm{H}_{2} \mathrm{CO}$ \\
1247 & 1236 & $\rho(\mathrm{CH})$ & $\mathrm{H}_{2} \mathrm{CO}$ \\
1178 & 1165 & $\omega(\mathrm{CH})$ & $\mathrm{H}_{2} \mathrm{CO}$ \\
1116 & 1096 & $\mathrm{C}-\mathrm{O}$ & POM \\
1089 & 1060 & $v(\mathrm{C}-\mathrm{O})$ & $\mathrm{EG}$ \\
1047 & $/$ & $v(\mathrm{C}-\mathrm{O})$ & $\mathrm{EG}$ \\
941 & 923 & $v(\mathrm{C}-\mathrm{O})$ & POM \\
905 & 885 & $v(\mathrm{C}-\mathrm{O})$ & POM \\
\hline \hline
\end{tabular}

$v$ : stretching; $\delta$ : bending; $\rho$ : rocking; $\omega$ : wagging.

portantly, theses species were not detected in rare gas matrix before rare gas sublimation indicating that COMs observed in the solid films come from radical reactivity during the rare gas sublimation. The GA C $=\mathrm{O}$ stretching mode at $1746 \mathrm{~cm}^{-1}$ is clearly visible. Two bands at 1089 and $1047 \mathrm{~cm}^{-1}$ hint that EG is also present in the short-irradiation experiment. Nevertheless, it is also interesting to note that glyceraldehyde (GCA) and glycerol (GCO) have similar frequencies and they could also contribute to these bands. All
Table 5. GA, EG, and POM column densities $\left(\mathrm{mol} \mathrm{cm}^{-2}\right)$ observed in solid films after VUV photolysis and rare gas desorption.

\begin{tabular}{cccc}
\hline \hline \multicolumn{4}{c}{ Ar experiments } \\
\hline \multirow{3}{*}{$50 \mathrm{~K}$} & GA & EG & POM \\
\cline { 2 - 4 } $150 \mathrm{~K}$ & $2 \pm 0.2 \times 10^{15}$ & $4 \pm 0.3 \times 10^{15}$ & $4 \pm 0.2 \times 10^{15}$ \\
\hline \multicolumn{4}{c}{ Xe experiments } \\
\hline \multirow{3}{*}{$85 \mathrm{~K}$} & GA & EG & POM \\
\cline { 2 - 4 } $150.3 \times 10^{15}$ & $20 \pm 0.1 \times 10^{15}$ & $3 \pm 0.4 \times 10^{15}$ \\
$150 \mathrm{~K}$ & $1 \pm 0.3 \times 10^{15}$ & $20 \pm 0.1 \times 10^{15}$ & $4 \pm 0.2 \times 10^{15}$ \\
\hline \hline
\end{tabular}

frequencies and attributions are listed on Table 4. As previously suspected, infrared absorptions of methanol are not visible on the spectra of this experiment. It is a direct consequence of the limited production of $\mathrm{H}$-atoms from the photolysis of formaldehyde $\mathrm{H}_{2} \mathrm{CO}$.

We calculated the column densities of GA, EG, and POM (Table 5). At $50 \mathrm{~K}$ (ie after the Ar sublimation) EG and POM are the dominant products with a column densities of $4 \pm 0.310^{15} \mathrm{~mol}$ $\mathrm{cm}^{-2}$ each whereas the column densities of GA is $2 \pm 0.210^{15} \mathrm{~mol}$ $\mathrm{cm}^{-2}$. At $150 \mathrm{~K}$ as seen in Fig. 4, POM is efficiently formed and becomes the main product whereas there is no evolution on GA and EG column densities during the warming. This indicates that GA and EG are mainly formed during Ar sublimation when cage opening released ${ }^{\circ} \mathrm{HCO}$ and ${ }^{\circ} \mathrm{CH}_{2} \mathrm{OH}$ radicals that quickly react forming GA and EG (Butscher et al. 2015; Fedoseev et al. 2015; Chuang et al. 2015, 2017; Fedoseev et al. 2017). After the rare gas sublimation is complete, remaining radicals in low amount (below the detection limit) are isolated in a formaldehyde-dominated environment inhibiting radical-radical recombination but allowing chain-propagating $\mathrm{H}_{2} \mathrm{CO}$ polymerisation reactions as the temperature is increased.

This is confirmed with xenon experiments that allow matrix cage sublimation at higher temperature than in argon. Figure 5 displays the solid film infrared spectrum recorded after Xe desorption at $85 \mathrm{~K}$. The same products as previously are detected but now EG is the most abundant product (see Table 5). During the warming from $85 \mathrm{~K}$ to $150 \mathrm{~K}$ no evolution is observed on GA and EG column densities and only a small variation of POM (Fig. 6 and Table 5). Since the xenon desorption occurs at higher temperature than in Ar, radical-radical recombination is more efficient due to higher radical mobilities. The dramatic consumption of radical initiators -especially ${ }^{\circ} \mathrm{CH}_{2} \mathrm{OH}$ - inhibits formaldehyde polymerisation in the solid film explaining the small POM formation during the warming. This may also indicate that ${ }^{\circ} \mathrm{CH}_{2} \mathrm{OH}$ radical is a more important radical in chain-propagating $\mathrm{H}_{2} \mathrm{CO}$ polymerization reactions than 'HCO radical. This point will be clarified in the theoretical part

Attributions were also confirmed using Temperature Programmed Desorption (TPD) experiment with a quadrupole mass spectrometer. The objective of such an experiment is to identify the desorbing molecules by mass spectrometry. Indeed, desorption temperature and fragmentation pattern are inherent to a molecular structure. Figure 7 shows the TPD graph from $125 \mathrm{~K}$ to $300 \mathrm{~K}$, after the formaldehyde desorption. At least seven desorption peaks are observed during the TPD experiments indicating that more than the three previously assigned products have been formed in the experiments (Fig. 7).

The first desorption peaks at $160 \mathrm{~K}$ can be assigned to GA from signal at $\mathrm{m} / \mathrm{z} 60$ and $\mathrm{m} / \mathrm{z}$ 43. (Fedoseev et al. 2017). EG is also 


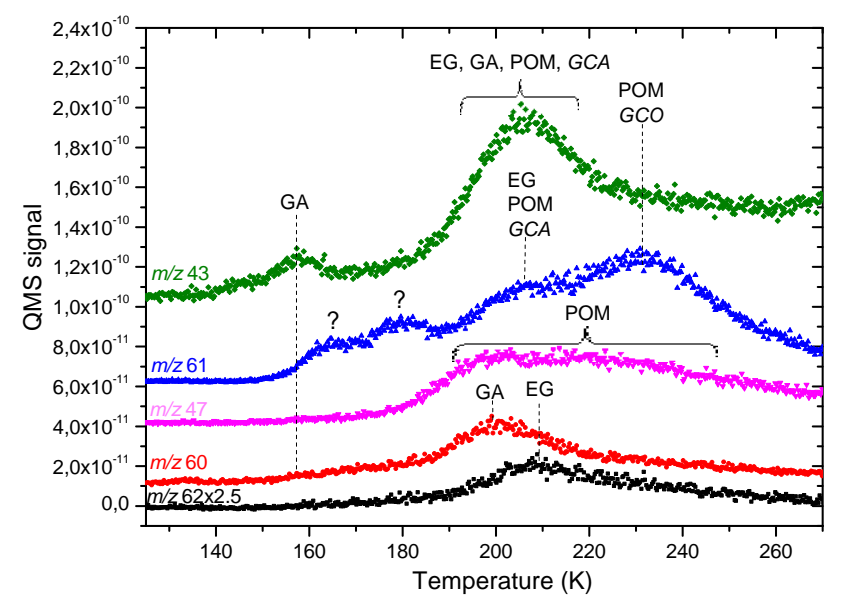

Figure 7. Temperature Programmed Desorption (TPD) spectra of the solid film formed after rare gas desorption step of the photolysis at $12 \mathrm{~K}(\lambda>120 \mathrm{~nm}, 30 \mathrm{~min})$ of $\mathrm{H}_{2} \mathrm{CO} / \mathrm{Ar}=2 / 1000$ matrix. $\mathrm{m} / z$ 43: $\mathrm{CHOCH}_{2}^{+} ; \mathrm{m} / \mathrm{z}$ 47: $\mathrm{HOCH}_{2} \mathrm{O}^{+} ; \mathrm{m} / \mathrm{z}$ 60: $\mathrm{HOCH}_{2} \mathrm{CHO}^{+*} ; \mathrm{m} / \mathrm{z}$ 61: $\mathrm{HOCH}_{2} \mathrm{CH}_{2} \mathrm{O}^{+} / \mathrm{HOCH}_{2} \mathrm{OCH}_{2}^{+} ; m / z$ 62: $\mathrm{HOCH}_{2} \mathrm{CH}_{2} \mathrm{OH}^{+}$. GA: $m / z$ 61, 43; EG: $m / z$ 62, 61, 43; POM: $m / z$ 61, 47, 43; GCA: $m / z$ 61, 43; GCO: $m / z$ 6143 . GCA and $G C O$ detections are only tentative

easily assigned from its characteristic desorption around $210 \mathrm{~K}$ for $\mathrm{m} / \mathrm{z}$ 62. These two products were previously detected using infrared spectroscopy. The third product detected by infrared spectroscopy POM is also confirmed by the QMS analysis from its characteristic fragments at $m / z$ 47, 43, and 61 (Duvernay et al. 2014). It has to be noted that $\mathrm{m} / \mathrm{z} \quad 47$ is only due to POM fragmentation whereas $\mathrm{m} / \mathrm{z}, 43$ and 61 are also common fragments to other molecules such as GA, EG. This explain why the evolution of $m / z, 47$ is different from the one observed for $\mathrm{m} / \mathrm{z} 43$ and 61 . In ${ }^{13} \mathrm{C}$ experiment, $\mathrm{m} / \mathrm{z}$ 43 becomes $\mathrm{m} / \mathrm{z}, 45$ and $\mathrm{m} / \mathrm{z} 47$ becomes $\mathrm{m} / \mathrm{z}$ 49. These matches different fragments of polyoxymethylene (POM). This is shown in Figure 8 that displays different fragmentation patterns for polyoxymethylene (POM) according to terminal groups. For example the fragment at $\mathrm{m} / \mathrm{z} 43$ indicates that the polymerisation process has been initiated/terminated by ${ }^{\circ} \mathrm{HCO}$ radical while the fragment at $m / z 47$ indicates ${ }^{\circ} \mathrm{CH}_{2} \mathrm{OH}$ radical was the initiator/terminator. Also, an interesting point is their desorption temperature ranging from $180 \mathrm{~K}$ to $250 \mathrm{~K}(\mathrm{~m} / \mathrm{z} 47)$. It depends on the length of the polymer and increases when the polymer grows (Duvernay et al. 2014). Two small peaks at $165 \mathrm{~K}$ and $180 \mathrm{~K}$ on the signal $\mathrm{m} / \mathrm{z} 61$ are coming from the desorption on unknown products.

The desorption peak starting at around $185 \mathrm{~K}$ for $\mathrm{m} / \mathrm{z} 43$ cannot be explained by the desorption of POM only. We also observe in this temperature range co-desorption with GA at $200 \mathrm{~K}(\mathrm{~m} / \mathrm{z}, 60)$ and EG at $210 \mathrm{~K}(\mathrm{~m} / \mathrm{z}, 62)$. These two species contribute to the $\mathrm{m} / z, 43$ signal observed between $180 \mathrm{~K}$ and $220 \mathrm{~K}$ since POM, GA, and $\mathrm{EG}$ share this mass fragement. Co-desorption of glyceraldehyde $\left(\mathrm{HOCH}_{2} \mathrm{CH}(\mathrm{OH}) \mathrm{CHO}\right)$ as reported by Fedoseev et al. (2017) cannot also be excluded since the desorption temperature for this compound is observed at $215 \mathrm{~K}$ and the $\mathrm{m} / z, 43$ and 61 are the most intensive peaks (Fedoseev et al. 2017). Thus, the co-desorption observed between $180 \mathrm{~K}$ and $220 \mathrm{~K}$ can be explained by the fact that GA, EG, and other COMs have been trapped in POM and are driven away from the sample holder during the POM desorption.

Finally, the last desorption peak is observed around $235 \mathrm{~K}$ for $m / z, 61, m / z, 47$, and $m / z, 43$. The presence of $m / z, 47$ indicates POM desorption but again other contribution cannot be excluded. Com-

\section{Fragmentation pattern for POM with $\mathrm{HCO}$ end group}

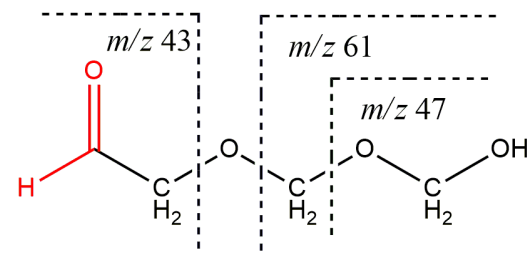

Fragmentation pattern for POM with $\mathrm{CH}_{2} \mathrm{OH}$ end group

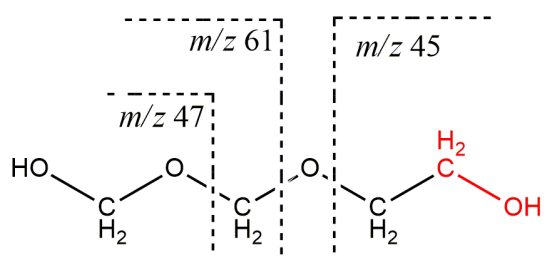

Figure 8. Polyoxymethylene fragmentation pattern according to end-groups.

plex molecules such as glycerol $\left(\mathrm{GCO}, \mathrm{HOCH}_{2} \mathrm{CH}(\mathrm{OH}) \mathrm{CH}_{2} \mathrm{OH}\right)$ may also contribute to the desorption peak observed at $235 \mathrm{~K}(\mathrm{Fe}-$ doseev et al. 2017) for $\mathrm{m} / \mathrm{z} 61$. The difficulty of mass assignments comes from the fact that EG, POM but also GCA, and GCO all share the same characteristic fragments $\mathrm{m} / \mathrm{z}, 43$ and 61 . The suspected formation of both GCA and GCO can be explained by the mechanism prosposed by Fedoseev et al. (2017). Both GA and EG -two products observed in our experiments- can participate in $\mathrm{H}$-induced reactions, producing two carbon bearing radical intermediates $\mathrm{HOCH}_{2}{ }^{\circ} \mathrm{CHOH}$. This later, in turn, can react in a barrierless radical-radical recombination with ${ }^{*} \mathrm{HCO}$ or ${ }^{{ }} \mathrm{CH}_{2} \mathrm{OH}$ radicals resulting in the formation of GCA and GCO respectively (Fedoseev et al. 2017). In a such mechanism, sugar formation (e.g. GCA and GCO) are competitive reactions with formaldehyde polymerisation (e.g. POM formation). However, more experiments are needed to confirm the GCA and GCO formation in our experiments.

Thus, after radical recombination, detected products are polyoxymethylene (POM), glycolaldehyde (GA), ethylene glycol (EG) and possibly glyceraldehyde (GCA) and glycerol (GCO).

\subsection{Theoretical results}

In this section, we aim at providing a possible formation mechanism of POM, using state-of-the-art quantum calculations. We considered the two following polymerisation reactions :

$$
\begin{aligned}
& \cdot \mathrm{HCO} \stackrel{\mathrm{H}_{2} \mathrm{CO}}{\longrightarrow} \mathrm{HC}(\mathrm{O}) \mathrm{CH}_{2} \mathrm{O} \cdot \stackrel{\mathrm{H}_{2} \mathrm{CO}}{\longrightarrow} \mathrm{HC}(\mathrm{O}) \mathrm{CH}_{2} \mathrm{OCH}_{2} \mathrm{O} \stackrel{\mathrm{H}_{2} \mathrm{CO}}{\longrightarrow} \ldots \text { (1) } \\
& \cdot \mathrm{CH}_{2} \mathrm{OH} \stackrel{\mathrm{H}_{2} \mathrm{CO}}{\longrightarrow} \mathrm{HOCH}_{2} \mathrm{CH}_{2} \mathrm{O} \stackrel{\mathrm{H}_{2} \mathrm{CO}}{\longrightarrow} \mathrm{HOCH}_{2} \mathrm{CH}_{2} \mathrm{OCH}_{2} \mathrm{O} \cdot \stackrel{\mathrm{H}_{2} \mathrm{CO}}{\longrightarrow} \text { (2) }
\end{aligned}
$$

For both reactions (1) and (2), the initiation step can a priori proceed via the two addition reactions : either a $\mathrm{C}-\mathrm{C}$ bond (steps (3) and (5)) or a $\mathrm{C}-\mathrm{O}$ bond (steps (4) and (6)) is formed.

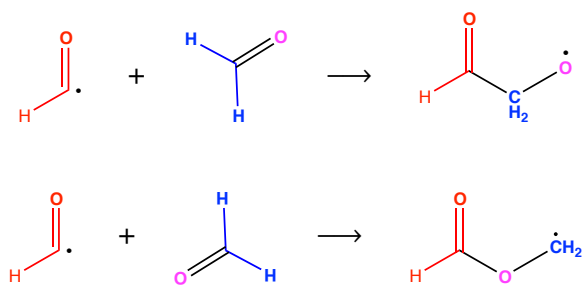


<smiles>CO[C@H](C)O[C@H](C)OC</smiles>

\subsubsection{Initiation steps for the ${ }^{\circ} \mathrm{HCO} /{ }^{\circ} \mathrm{CH}_{2} \mathrm{OH}+\mathrm{H}_{2} \mathrm{CO}$ polymerisation}

The results for the initiation steps (3), (4), (5) and (6) at the UCCSD(T)-F12 level are shown on Figure 9, where the reaction path for reaction (1) appears on the right-hand side of the figure and the one for reaction (2) appears on the left-hand side. For both reactions, the $\mathrm{C}-\mathrm{O}$ bond formation appears to be much less favoured than the

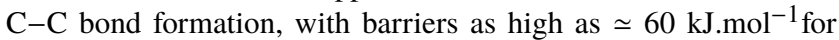
the former and up to $\simeq 30 \mathrm{~kJ}^{\mathrm{mol}}{ }^{-1}$ for the latter. Interestingly, the formyloxymethyl radical $\mathrm{HC}(\mathrm{O}) \mathrm{OCH}_{2}$ is thermodynamically more stable than the formylmethoxy radical $\mathrm{HC}(\mathrm{O}) \mathrm{CH}_{2} \mathrm{O}^{*}$ (the same is true although less pronounced for the ${ }^{\circ} \mathrm{CH}_{2} \mathrm{OH}$ counterpart). Under the current experimental conditions (@ 35 K) however, the "C-O" products are unlikely to be formed. Thus, only the initiation step (3) and (5) for reactions (1) and (2) respectively will be considered in the following. For this step, reaction (2) is more likely to happen than reaction (1) at low temperatures, with a barrier of $\simeq 12 \mathrm{~kJ} . m o l^{-1}$ for

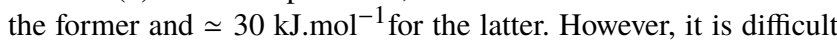
to estimate if a barrier of $\simeq 12 \mathrm{~kJ}^{-m_{0}}{ }^{-1}$ is low enough under the experimental conditions (@35 K) so that the polymerisation reaction can be initiated. A comparison at the same level of calculation with the hydrogenation reaction of $\mathrm{CO}$, known to occur at temperatures as low as $3 \mathrm{~K}$ (Pirim \& Krim 2011) will be informative with regard to this question and will be discussed in section 3.2.3. Even if we were to assume that the initiation step was possible, one has to check if the next formaldehyde additions proceed through lower energy barriers than the first one, that is if the initiation step is the rate-determining step for the formaldehyde polymerisation reaction. A careful inspection of the propagation steps for both reactions (1) and (2) will help providing an answer.

\subsubsection{Propagation steps for the ${ }^{\circ} \mathrm{HCO} /{ }^{\bullet} \mathrm{CH}_{2} \mathrm{OH}+\mathrm{H}_{2} \mathrm{CO}$ polymerisation}

We calculated the reaction paths for the next two propagation steps of reactions (1) and (2). The reaction paths at both B3LYP and $\mathrm{UCCSD}(\mathrm{T})$-F12 levels of theory are shown for each reaction in Figure 10 and Figure 11, respectively, and the corresponding energy values are reported in table 6 . For each path, the reference energy corresponds to the sum of energies of the ${ }^{\circ} \mathrm{HCO}$ (resp. ${ }^{\circ} \mathrm{CH}_{2} \mathrm{OH}$ ) radical and of $n \mathrm{H}_{2} \mathrm{CO}$ moieties $(n \in[1-3])$ calculated separately, corrected by the ZPE at the B3LYP level. Each step of the reaction paths corresponds to the addition of a formaldehyde molecule. Among the possible conformers of the products, only the most stable one was kept for the reaction path.

As can be seen on Figure 10 and Figure 11, both DFT and coupled cluster calculations show the two following important results : (a) the polymerisation of formaldehyde initiated by both ${ }^{\circ} \mathrm{HCO}$ and ${ }^{\circ} \mathrm{CH}_{2} \mathrm{OH}$ radicals is thermodynamically favourable and (b) the energy barriers of the propagation steps all lie lower (or nearly) than

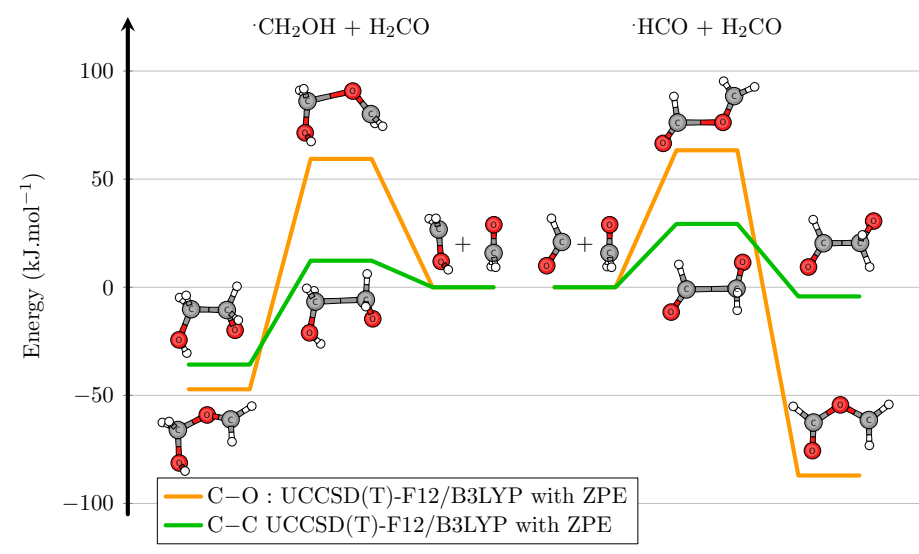

Figure 9. Left: ${ }^{\cdot} \mathrm{CH}_{2} \mathrm{OH}+\mathrm{H}_{2} \mathrm{CO}$ reaction paths for the $\mathrm{C}-\mathrm{C}$ bond formation (green) and $\mathrm{C}-\mathrm{O}$ bond formation (yellow) in the initiation steps (5) and (6). Right: ${ }^{\circ} \mathrm{HCO}+\mathrm{H}_{2} \mathrm{CO}$ reaction paths for the $\mathrm{C}-\mathrm{C}$ bond formation (green) and $\mathrm{C}-\mathrm{O}$ bond formation (yellow) in the initiation steps (3) and (4) respectively (See text).

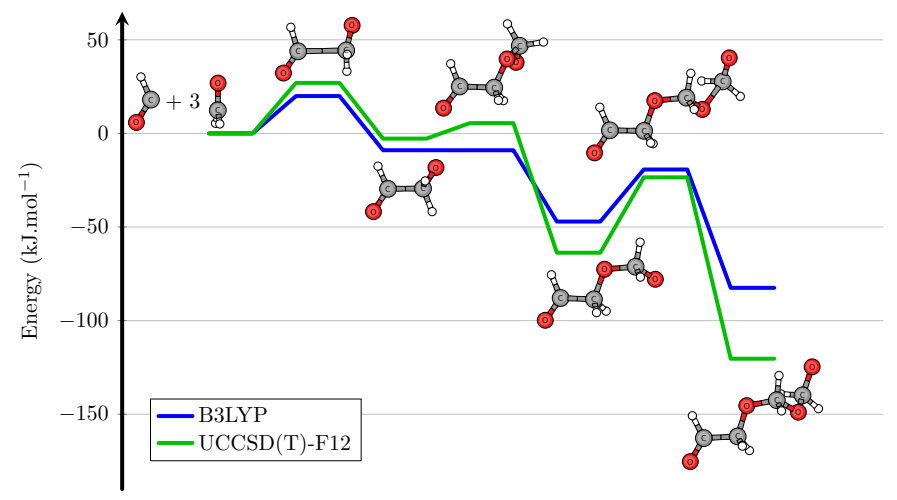

Figure 10. Reaction path of the initiation step ( $\mathrm{C}-\mathrm{C}$ bond formation) and the first two propagation steps for reaction (1) (See text).

$[! h]$

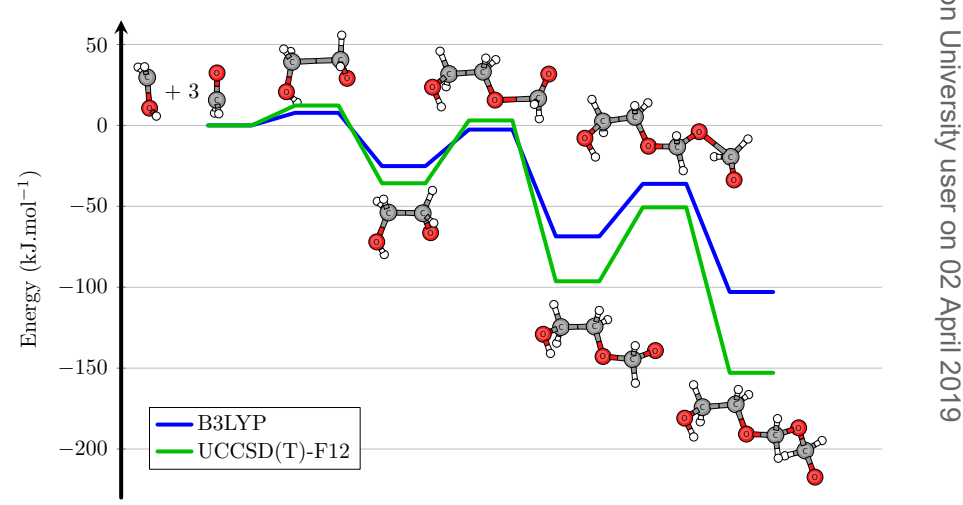

Figure 11. Reaction path of the initiation step (C-C bond formation) and the first two propagation steps for reaction (2) (See text). 
$[! \mathrm{h}]$

Table 6. B3LYP and UCCSD(T)-F12 energies (ZPE corrected, in $\mathrm{kJ} . \mathrm{mol}^{-1}$ ) of reactants, transition states and products of the first three steps of polymerisation reactions of formaldehyde from ${ }^{\circ} \mathrm{HCO}$ and ${ }^{\circ} \mathrm{CH}_{2} \mathrm{OH}$ radicals.

\begin{tabular}{|c|c|c|}
\hline Species of reaction (1) & $\begin{array}{l}\text { B3LYP } \\
\left(\mathrm{kJ} \cdot \mathrm{mol}^{-1}\right)\end{array}$ & $\begin{array}{l}\operatorname{UCCSD}(\mathrm{T})-\mathrm{F} 12 \\
\left(\mathrm{~kJ} \cdot \mathrm{mol}^{-1}\right)\end{array}$ \\
\hline$\cdot \mathrm{HCO}+\mathrm{H}_{2} \mathrm{CO}$ & 0.00 & 0.00 \\
\hline TS1 & +20.0 & +27.0 \\
\hline $\mathrm{HC}(\mathrm{O}) \mathrm{CH}_{2} \mathrm{O}^{\circ}$ & -8.98 & -2.77 \\
\hline TS2 & -8.99 & +5.52 \\
\hline $\mathrm{HC}(\mathrm{O}) \mathrm{CH}_{2} \mathrm{OCH}_{2} \mathrm{O}^{-}$ & -47.1 & -63.7 \\
\hline TS3 & -19.3 & -23.5 \\
\hline $\mathrm{HC}(\mathrm{O})\left(\mathrm{CH}_{2} \mathrm{O}\right)_{2} \mathrm{CH}_{2} \mathrm{O}^{\circ}$ & -82.5 & -120.3 \\
\hline \multicolumn{3}{|l|}{ Species of reaction (2) } \\
\hline$\cdot \mathrm{CH}_{2} \mathrm{OH}+\mathrm{H}_{2} \mathrm{CO}$ & 0.00 & 0.00 \\
\hline TS1 & +7.77 & +12.3 \\
\hline $\mathrm{HOCH}_{2} \mathrm{CH}_{2} \mathrm{O}^{\circ}$ & -25.2 & -35.8 \\
\hline TS2 & -2.56 & +3.06 \\
\hline $\mathrm{HOCH}_{2} \mathrm{CH}_{2} \mathrm{OCH}_{2} \mathrm{O}^{-}$ & -68.6 & -96.3 \\
\hline TS3 & -36.1 & -50.6 \\
\hline $\mathrm{HOCH}_{2}\left(\mathrm{CH}_{2} \mathrm{O}\right)_{2} \mathrm{CH}_{2} \mathrm{O}^{\circ}$ & -102.9 & -152.9 \\
\hline
\end{tabular}

the initial energy of the reactants, showing that the rate-determining step for the polymerisation is namely the initiation step. If the first barrier can be overcome, the polymerisation reaction would proceed and would be driven by the formation of even more thermodynamically stable species, which is consistent with the detection of POM in our experiments. Before focusing on the rate-determining step, it is interesting to analyse the differences between the DFT and coupled cluster results on one hand and on the differences between both reaction paths on the other hand, from the values of Table 6 .

For both reactions, the DFT method underestimates energy barriers as well as exothermicities compared to the coupled cluster ones. The only exception regarding exothermicities appears for the formylmethoxy radical $\mathrm{HC}(\mathrm{O}) \mathrm{CH}_{2} \mathrm{O}^{\circ}$, which is found to be about $6 \mathrm{~kJ} \cdot \mathrm{mol}^{-1}$ less stable and almost isoenergetic with the reactants at the coupled cluster level. Apart from this case, the differences between DFT and coupled cluster values are particularly well pronounced for the second propagation step with a difference in the energy barrier up to $14 \mathrm{~kJ} \cdot \mathrm{mol}^{-1}$ and in the exothermicity up to $22 \mathrm{~kJ} \mathrm{~mol}^{-1}$ for reaction (2). At the UCCSD(T)-F12 level, the energy release of each propagation step remains more or less constant $\left(\simeq 60 \mathrm{~kJ} \cdot \mathrm{mol}^{-1}\right)$, and this for each reaction, whereas they range from 35 to $43 \mathrm{~kJ} \mathrm{~mol}^{-1}$ at the DFT level.

Regarding the differences between the two reaction paths, both methods predict more stable products in reaction (2) than in reaction (1) : a plausible explanation is the possibility of an hydrogen bond between the $\mathrm{O}-\mathrm{H}$ group brought by the hydroxymethyl radical and the oxygen of formaldehyde, which stabilises the newly formed radical and is absent in the case of the formyl radical. This is particularly obvious for the hydroxymethylmethoxy radical $\mathrm{HOCH}_{2} \mathrm{CH}_{2} \mathrm{O}$.

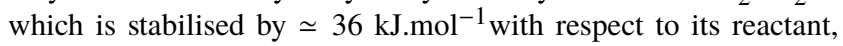
whereas the formylmethoxy radical $\mathrm{HC}(\mathrm{O}) \mathrm{CH}_{2} \mathrm{O}^{*}$ is only stabilised by $\simeq 3 \mathrm{~kJ} \mathrm{~mol}^{-1}$. Another feature of both reaction paths is that the first energy barrier is lower for reaction (2), indicating that this reaction could possibly be the dominant mechanism for the formation of POM. [!h]

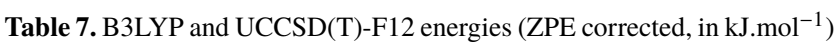
of reactants, transition states and products of the hydrogenation reaction of $\mathrm{CO}$

\begin{tabular}{lll}
\hline \hline & $\begin{array}{l}\text { B3LYP } \\
\left(\mathrm{kJ} . \mathrm{mol}^{-1}\right)\end{array}$ & $\begin{array}{l}\mathrm{UCCSD}(\mathrm{T})-\mathrm{F} 12 \\
\left(\mathrm{~kJ} . \mathrm{mol}^{-1}\right)\end{array}$ \\
$\mathrm{H}+\mathrm{CO}$ & 0.00 & 0.00 \\
TS & 1.88 & 11.2 \\
${ }^{\mathrm{HCO}}$ & -85.3 & -56.5 \\
\hline \hline
\end{tabular}

\subsubsection{Interpretation of the experimental results}

The calculated reaction paths for both reactions (1) and (2) have shown that these reactions are good candidates to explain the polymerisation of formaldehyde into POM, provided the first energy barrier can be overcome. Since the DFT method is known to underestimate energy barriers, we will refer in the following discussion to the more reliable values obtained by the UCCSD(T)-F12 method. The lowest barrier was found to be $12.3 \mathrm{~kJ}^{\mathrm{mol}}{ }^{-1}$ for the addition of formaldehyde on the hydroxymethyl radical (See Table 6). In order to estimate if this barrier can be overcome at $35 \mathrm{~K}$, one can compare it to the barrier of the elementary reaction of hydrogenation of CO. Pirim and Krim (Pirim \& Krim 2011) have recently shown that the reaction of non-energetic $\mathrm{H}$-atoms with $\mathrm{CO}$ can occur to form formyl radicals at temperatures as low as $3 \mathrm{~K}$. We calculated the energy barrier for this reaction at DFT and UCCSD(T)-F12 levels and the results are reported in Table 7. As can be seen, if one would trust the DFT values, one would conclude that the small energy barrier of $1.88 \mathrm{~kJ}^{\mathrm{mol}}{ }^{-1}$ and the high exothermicity are compatible with the experimental observations. The UCCSD(T)-F12 energy barrier is however much higher $\left(11.2 \mathrm{~kJ} . \mathrm{mol}^{-1}\right)$ and very close to the energy barrier of reaction 2 . If one trusts the coupled cluster value, this gives an indication that such $\mathrm{a} \simeq 10 \mathrm{~kJ}^{\mathrm{mol}} \mathrm{m}^{-1}$ barrier is obviously not contradictory with the fact that this reaction efficiently occurs at very low temperature. Hence, one can put forward the following hypotheses to explain the formation of POM :

(i) There is a possible "cage effect" of the desorbing Ar atoms that could artificially stabilise the first transition state and thus lower the reaction barrier. It seems however difficult to support experimentally this idea by probing the Ar matrix at its desorbing temperature in order to have an idea on the local environment of the reactants.

(ii) Tunneling effects are known to be important at very low temperature, mainly for light species. In the case of the hydrogenation of $\mathrm{CO}$, the tunneling of $\mathrm{H}$-atom certainly enhances the reactivity. In our case, tunneling effect would correspond to a $\mathrm{C}-\mathrm{C}$ bond formation. The imaginary frequencies of the transition states, $263 i \mathrm{~cm}^{-1}$ and $286 i \mathrm{~cm}^{-1}$ for the initiation steps of reactions (1) and (2), respectively, indicate that, in the framework of the simple standard Eckart model, the barriers are not thin enough for the tunneling to be important. However, important tunneling effects for heavy atoms are known to occur at very low temperature (Borden 2016; Meisner \& Kästner 2016; Goumans \& Andersson 2010) and tunneling has recently been recognised as the third reactivity paradigm (Schreiner 2017). It would certainly be interesting to investigate further the role of tunneling in the POM formation in the light of these recent findings.

(iii) More likely, the energy release from the first step of reaction (2) 
or from a fast radical-radical recombination reaction to form EG or GA could possibly be transferred to the reactants of reaction (1) and enable the barrier to be overcome.

Finally, the termination step can occur either with a recombination with a $\mathrm{HCO}$ or ${ }^{\circ} \mathrm{CH}_{2} \mathrm{OH}$ radical. This recombination step between two radicals is expected to proceed without any barrier and should thus be fast. The length of the POM chain would then depend on the amount of the remaining radicals as the Ar desorption is fully over. This is consistent with the mass spectra recorded between 150 and $230 \mathrm{~K}$ (Fig. 7) that clearly shows chain-length distribution as well as both ${ }^{\circ} \mathrm{HCO}$ and ${ }^{\circ} \mathrm{CH}_{2} \mathrm{OH}$ end groups.

\section{ASTROCHEMICAL IMPLICATIONS}

The presence of polyoxymethylene in comets is an exciting story that started in 1986. During the Halley comet flyby by the Giotto mission, the PICCA instrument (Positive Ion Cluster Composition Analyser) recorded mass spectra displaying a periodic pattern with repeating units of $\mathrm{m} / \mathrm{z}, 16: 14$ consistent with an $-\mathrm{O}-$ and $-\mathrm{CH}_{2}-$ addition/loss. At that time, this pattern was identified as being compatible with formaldehyde polymers, also referred to as polyoxymethylene (POM) (Huebner 1987). Latter, Mitchell et al. (1989) showed that this regular pattern is generally characteristic of any kind of CHO-bearing molecules that include POM-like structures. Recently, a similar pattern was found by the Ptolemy instrument of the Rosetta mission (Wright et al. 2015) strengthening the POM detection in cometary nucleus. However, this is to be tempered since recent re-investigation of Ptolemy data and comparison with data from two others mass spectrometers on-board the Rosetta mission, COSAC and ROSINA suggest that the detection of polyoxymethylene by Ptolemy instrument cannot be confirmed (Altwegg et al. 2017). They calibrated the ROSINA flight spare instrument with commercially available polymer. POM was thermally desorbed in a vacuum chamber and then connected to ROSINA flight spare instrument. From the fragmentation pattern they observed, they concluded that thermal desorption of POM mostly produce monomer $(\mathrm{m} / \mathrm{z} 28$ 30 ), and only very little dimer or longer chains and it does not produce the observed periodic pattern with repeating units of $\mathrm{m} / \mathrm{z}, 16: 14$ as observed on Ptolemy instrument. In addition, the ROSINA results obtained in laboratory are not compatible with the suggestion made by Wright et al. (2015) that POM is responsible for high peak on $\mathrm{m} / z 91$ and peaks between $\mathrm{m} / z 55$ and 62 . We would like to make comments on these results. It is well known that commercially available POM thermally decompose at temperature higher than $40^{\circ} \mathrm{C}$ into formaldehyde. Commercially available POMs mainly consist of long chain-length polymers that cannot sublimate easily. Instead, at temperature higher than $40^{\circ} \mathrm{C}$, they start to depolymerise into $\mathrm{H}_{2} \mathrm{CO}$ monomer (Duvernay et al. 2014; Le Roy et al. 2012). However, the mass spectra of formaldehyde oligomers (i.e. short chainlength POMs) are really different from the ones of commercially available POMs and present high similarities with data recorded by Ptolemy instrument supporting POM identification in cometary nuclei made by both PICCA and Ptolemy instruments (Duvernay et al. 2014). Results from this study also bring some new elements that strengthen the likely formation of POM on cometary nuclei based on formaldehyde polymerisation initiated by radicals. The figure 12 displays the mass spectra comparison between the POM desorbing from our sample holder at $260 \mathrm{~K}$ with some peaks extracted from the Ptolemy spectra (Wright et al. 2015). Those peaks at $\mathrm{m} / \mathrm{z} 31,43$, $45,47,57,59,61,73$ have been proposed to be polyoxymethylene (Wright et al. 2015) originating from the surface of the comet 67P.

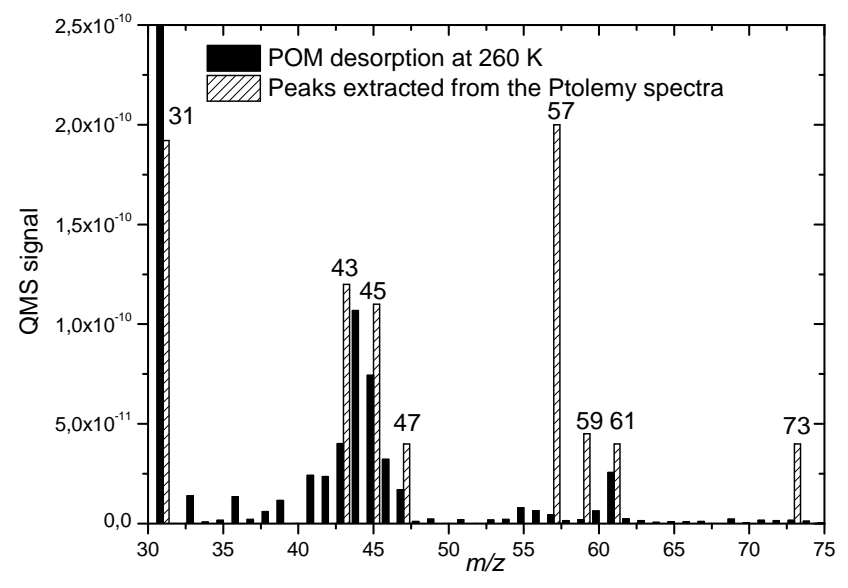

Figure 12. Mass spectrum of POM recorded at $260 \mathrm{~K}$ compared with extracted peaks from the Ptolemy spectra. $\mathrm{m} / \mathrm{z} 44$ is related to $\mathrm{CO}_{2}$ contamination.

These data fit well the mass spectra of volatile POM recorded at 260 K except three masses at $m / z, 57,59$, and 73. Mass spectra recorded by Ptolemy instrument do not reflect a single idealized compounds with its ends terminated by $\mathrm{H}$-atoms. Rather they indicate a number of different terminations with chain running as $-\mathrm{CH}_{2} \mathrm{O}-$. For instance, peaks at $\mathrm{m} / z, 57,59$ and 73 on Ptolemy spectrum result $\mathrm{POM}$ fragmentation with $-(\mathrm{CO}) \mathrm{CH}_{3}$ termination that is unlikely in our conditions since the only possible terminations are $-\mathrm{CHO}$ or $-\mathrm{CH}_{2} \mathrm{OH}$. This may explain the absence of peaks at $\mathrm{m} / z$ 57, 59, and 73 on our sample. The question therefore remains whether POMs are an important component of comets and more laboratory/theoretical studies and space missions will be needed to close this passionate debate.

\section{CONCLUSION}

We report new laboratory experiments on the low-temperature solid state formation of formaldehyde polymer polyoxymethylenethrough radical-induced reactivity from VUV photolysis of formaldehyde in Ar matrix. We show, based on experimental finding and quantum calculations, the ability of free radicals to react at low temperature with others on the double bonds of unsaturated molecules initiating COMs formation such as GA, EG, and formaldehyde polymerisation. This formation mechanism based on radical-induced reactivity is likely in interstellar ices or cometary grains and supports the presence of COMs and POM in cometary nuclei. In addition the fragmentation pattern we observe with mass spectroscopy for short chain-length POM polymers is consistent with the data collected by the Ptolemy instrument on-board the Rosetta mission.

\section{ACKNOWLEDGEMENTS}

The project leading to this publication has received funding from Excellence Initiative of Aix-Marseille University - A*MIDEX, a French "Investissements d'Avenir programme". This work was also supported by the PCMI (Physique et Chimie du Milieu Interstellaire) program and The CNES (Centre National d'Etudes spatiales). We 
also thank G. Knizia for freely providing the renmol script for generating the molecular cartoons.

\section{REFERENCES}

Abe H., Takeo H., Yamada K. M., 1999, Chemical physics letters, 311, 153 Abou Mrad N., Duvernay F., Theulé P., Chiavassa T., Danger G., 2014, Analytical chemistry, 86, 8391

Abou Mrad N., Duvernay F., Chiavassa T., Danger G., 2016, Monthly Notices of the Royal Astronomical Society, 458, 1234

Altwegg K., et al., 2017, Monthly Notices of the Royal Astronomical Society, $469, \mathrm{~S} 130$

Becke A., 1993, J. Chem. Phys, 98, 5648

Bennett C. J., Kaiser R. I., 2007, The Astrophysical Journal, 661, 899

Biver N., et al., 2014, Astronomy \& Astrophysics, 566, L5

Borden W. T., 2016, Wiley Interdisciplinary Reviews: Computational Molecular Science, 6, 20

Butscher T., Duvernay F., Theule P., Danger G., Carissan Y., HagebaumReignier D., Chiavassa T., 2015, Monthly Notices of the Royal Astronomical Society, 453, 1587

Butscher T., Duvernay F., Danger G., Chiavassa T., 2016, Astronomy \& Astrophysics, 593, A60

Butscher T., Duvernay F., Rimola A., Segado-Centellas M., Chiavassa T., 2017, Physical Chemistry Chemical Physics, 19, 2857

Caro G. M., et al., 2002, Nature, 416, 403

Chuang K.-J., Fedoseev G., Ioppolo S., van Dishoeck E., Linnartz H., 2015, Monthly Notices of the Royal Astronomical Society, 455, 1702

Chuang K.-J., Fedoseev G., Qasim D., Ioppolo S., van Dishoeck E., Linnartz H., 2017, Monthly Notices of the Royal Astronomical Society, 467, 2552

Cottin H., Fray N., 2008, Space Science Reviews, 138, 179

Cottin H., Moore M. H., Bénilan Y., 2003, The Astrophysical Journal, 590, 874

Crovisier J., Bockelée-Morvan D., Biver N., Colom P., Despois D., Lis D. C., 2004, Astronomy \& Astrophysics, 418, L35

Danger G., Rimola A., Mrad N. A., Duvernay F., Roussin G., Theule P., Chiavassa T., 2014, Physical Chemistry Chemical Physics, 16, 3360

Deglmann P., May K., Furche F., Ahlrichs R., 2004, Chemical physics letters, 384,103

Dunning T. H., 1989, The Journal of Chemical Physics, 90, 1007

Duvernay F., Danger G., Theulé P., Chiavassa T., Rimola A., 2014, The Astrophysical Journal, 791, 75

Fedoseev G., Cuppen H., Ioppolo S., Lamberts T., Linnartz H., 2015, Monthly Notices of the Royal Astronomical Society, 448, 1288

Fedoseev G., Chuang K.-J., Ioppolo S., Qasim D., van Dishoeck E. F., Linnartz H., 2017, The Astrophysical Journal, 842, 52

Fray N., Bénilan Y., Biver N., Bockelée-Morvan D., Cottin H., Crovisier J., Gazeau M.-C., 2006, Icarus, 184, 239

Fuchs G., Cuppen H., Ioppolo S., Romanzin C., Bisschop S., Andersson S., van Dishoeck E., Linnartz H., 2009, Astronomy \& Astrophysics, 505, 629

Goesmann F., et al., 2015, Science, 349, aab0689

Goumans T. P. M., Andersson S., 2010, Monthly Notices of the Royal Astronomical Society, 406, 2213

Hättig C., Klopper W., Köhn A., Tew D. P., 2012, Chemical Reviews, 112, 4

Henderson B. L., Gudipati M. S., 2015, The Astrophysical Journal, 800, 66

Hiraoka K., Yamashita A., Yachi Y., Aruga K., Sato T., Muto H., 1995, The Astrophysical Journal, 443, 363

Hudson R. L., Moore M. H., Cook A. M., 2005, Advances in Space Research, 36,184

Huebner W., 1987, Science, 237, 628

Jacox M. E., 1988, The Journal of chemical physics, 88,4598

Jacox M. E., Milligan D. E., 1973, Journal of Molecular Spectroscopy, 47, 148

Kaiser R. I., Maity S., Jones B. M., 2015, Angewandte Chemie International Edition, 54, 195
Kunttu H., Seetula J., Räsänen M., Apkarian V., 1992, J. Chem. Phys., 96, 5630

Le Roy L., Briani G., Briois C., Cottin H., Fray N., Thirkell L., Poulet G., Hilchenbach M., 2012, Planetary and space science, 65, 83

Lee Y.-F., Chou W.-T., Johnson B. A., Tabor D. P., Sibert III E. L., Lee Y.-P., 2015, Journal of Molecular Spectroscopy, 310, 57

Meisner J., Kästner J., 2016, Angewandte Chemie International Edition, 55, 5400

Milligan D. E., Jacox M. E., 1969, J. Chem. Phys., 51, 277

Minissale M., Moudens A., Baouche S., Chaabouni H., Dulieu F., 2016, Monthly Notices of the Royal Astronomical Society, 458, 2953

Mitchell D., et al., 1989, Advances in Space Research, 9, 35

Nelander B., 1980, J. Chem. Phys., 73, 1026

Noble J., Theule P., Mispelaer F., Duvernay F., Danger G., Congiu E., Dulieu F., Chiavassa T., 2012, Astronomy \& Astrophysics, 543, A5

Öberg K. I., Garrod R. T., Van Dishoeck E. F., Linnartz H., 2009, Astronomy \& Astrophysics, 504, 891

Pettersson M., Khriachtchev L., Roozeman R.-J., Räsänen M., 2000, Chemical Physics Letters, 323, 506

Pirim C., Krim L., 2011, Phys. Chem. Chem. Phys., 13, 19454

Ryazantsev S. V., Feldman V. I., 2014, The Journal of Physical Chemistry A, 119,2578

Schreiner P. R., 2017, Journal of the American Chemical Society, 139, 15276

Schriver A., Schriver-Mazzuoli L., Vigasin A. A., 2000, Vibrational Spectroscopy, 23, 83

Schutte W., Allamandola L., Sandford S., 1993, Icarus, 104, 118

Stein C., Weser O., Schröder B., Botschwina P., 2015, Molecular Physics, 113,2169

Tew D. P., Klopper W., 2010, Molecular Physics, 108, 315

Vinogradoff V., Duvernay F., Danger G., Theulé P., Chiavassa T., 2011, Astronomy \& Astrophysics, 530, A128

Watanabe N., Shiraki T., Kouchi A., 2003, The Astrophysical Journal Letters, 588, L121

Watanabe N., Nagaoka A., Shiraki T., Kouchi A., 2004, The Astrophysical Journal, 616, 638

Weigend F., Ahlrichs R., 2005, Physical Chemistry Chemical Physics, 7 , 3297

Woods P. M., Slater B., Raza Z., Viti S., Brown W. A., Burke D. J., 2013, The Astrophysical Journal, 777, 90

Wright I., Sheridan S., Barber S., Morgan G., Andrews D., Morse A., 2015, Science, 349, aab0673 